\title{
Depression and Exposure to Electromagnetic Fields
}

Douglas B. McGregor
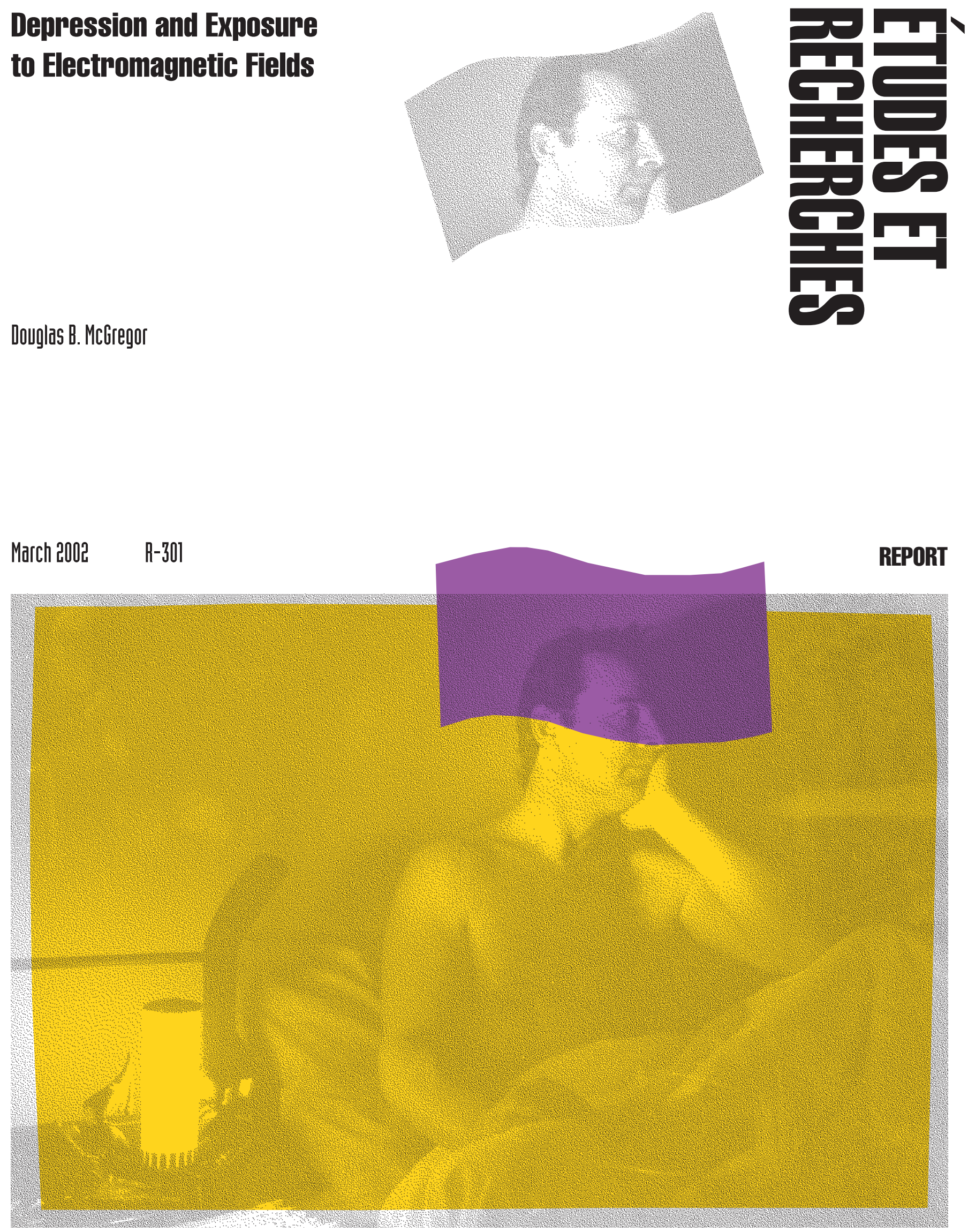


\section{arch, the key \\ esto \\ The Institut de recherche en santé et en sécurité du travail du Québec (IRSST, Québec Occupational Health and Safety Institute) is a scientific research agency committed to the identification and elimination at the source of occupational hazards, and the rehabilitation of workers who have suffered occupational injuries. With funding provided by the Commission pour la santé et la sécurité au travail du Québec (CSST, Québec Occupational Health and Safety Commission), the IRSST conducts, funds and contracts research aimed at reducing the human and financial costs of occupational accidents and diseases.}

For up-to-date information on research conducted or funded by the IRSST, subscribe to Prévention au travail, the free magazine published in conjunction with the CSST.

Reports describing the results of Institute research are available upon request from the Communications Division.

Legal Deposit

Bibliothèque nationale du Québec 2002

IRSST - Direction des communications 505, West De Maisonneuve Blvd., Montreal (Quebec)

$\mathrm{H} 3 \mathrm{~A} 3 \mathrm{C} 2$

Telephone: (514) 288-1551

Telecopieur: (514) 288-7636

publications@irsst.qc.ca

www.irsst.qc.ca

(C) Occupational Health and Safety

Research

Institute Robert-Sauvé

march 2002. 


\section{Depression and Exposure \\ to Electromagnetic Fields}

Douglas B. McGregor

Consultant

Clic Research

www.irsst.qc.ca

This publication is available free

of charge on the Web site.

This study was financed by the IRSST. The conclusions and recommendations are those of the authors. 


\section{Introduction}

Concern about the possible adverse psychological consequences of exposures to electromagnetic fields stems from reports in the late 1960's of symptoms such as headache, fatigue and disruption of sleep patterns in occupationally exposed extra-high voltage switchyard workers (Vyalow, 1967; Asanova \& Rakov, 1962). Although these early cross-sectional analysis reports had a number of weaknesses, their appearance stimulated considerable debate over the possible adverse health effects of occupational exposure to extremely low frequency electromagnetic fields. Nevertheless, these and other early reports have basically remained unconfirmed (Knave et al., 1979).

In 1979, Wertheimer \& Leeper presented the first study finding that environmental exposure to power frequency $(50$ and $60 \mathrm{~Hz}$ ) electric and magnetic fields might increase the risk of chronic disease, in this case mortality from cancer in children. At the same time, the first study was published that suggested a link between electromagnetic fields and suicide (Reichmanis et al., 1979). Any possible association of exposure to electromagnetic fields with depression is likely to be more difficult to evaluate than cancer, since these neurological health outcomes are not recorded in registries as are cancer mortalities; indeed there is normally no record, and the endpoint is even less clearly defined for depression than for suicide. In spite of such difficulties, more recent studies of depression in relation to electromagnetic fields have been pursued and this review is an attempt to evaluate the data they have produced in terms of electromagnetic fields being a possible risk factor for depressive symptoms.

\section{Depression}

Depression is one of the most commonly encountered states in clinical psychiatry and, with elation, predominates in mood disorders. Depression is also a part of everyday life. Sadness, 
"normal depression," is a response to defeat or disappointment. Depression, as a transient condition, may also occur as a reaction to significant, anticipated events, such as holidays or birthdays, a premenstrual phase or the post partum condition. These are not psychopathological conditions in themselves, but people predisposed to mood disorders may succumb at those times.

The mood disorders relevant to this review may be categorised as either bipolar (depressive and elated periods) or unipolar (depressions only). Bipolar disorders begin in younger people $(<25$ years) and have shorter cycles (time from onset of one episode to that of the next) than unipolar disorder (major depressive disorder). Bipolar mood disorder is broadly classified as bipolar I, bipolar II and cyclothymic disorder. In bipolar I, full-blown manic and major depressive episodes alternate. In bipolar II, major depressive episodes alternate with hypomanic (i.e., mild, nonpsychotic, excited) periods of short duration. In cyclothymic disorder, both elevated and depressive periods are less severe, may continue throughout life or may be a precursor of bipolar I and II disorders.

Unipolar mood disorder (or major depressive disorder) is defined (American Psychiatric Association, 1980) as at least one depressive episode, including grief lasting over one year and excluding anyone ever meeting criteria for a manic episode. It may be:

Melancholia (.e.g., marked agitation, weight loss, pathological guilt, early morning insomnia, diurnal variation in mood and activity with a nadir in the morning, loss of capacity to experience pleasure);

Atypical depressive disorder (course fluctuates, with mixtures of phobic anxious features, hyperphagia, evening worsening, initial insomnia and morning hypersomnolence;

Dysthymic disorder (intermittent or chronic low-grade depression of insidious early onset, typically $<21$ years).

Common causes of depression are:

$\underline{\text { Pharmacological }} \quad$ steroidal contraceptives; reserpine; $\alpha$-methyldopa; anticholine-esterase insecticides; amphetamine withdrawal; cimetidine; indomethacin; phenothiazines; thallium; mercury; cycloserine; vinblastine; vincristine; 
Infectious influenza; viral pneumonia; viral hepatitis; infectious mononucleosis; tuberculosis; general paresis (tertiary syphilis).

Endocrine hypo- and hyper-thyroidism; hyperparathyroidism; Cushing`s disease; Addison`s disease;

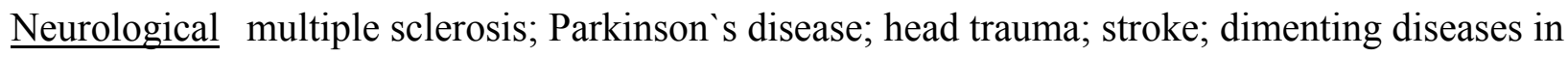
early stages; sleep apnoea;

Nutritional pellagra; vitamin $\mathrm{B}_{12}$ deficiency;

Neoplastic cerebral tumours; cancer of the head of the pancreas; metastasis.

It is considered that about $25 \%$ of people experience some form of affective disturbance, but the lifetime risk for clinically significant mood disorders is probably about $12 \%$ in men and $18 \%$ in women. Rates are higher in women for the milder forms of depression and nearly equal in men and women in manic-depression. Clinical depression is limited to those people with a special vulnerability.

Sociocultural factors modify clinical manifestations, e.g., somatic complaints, worry, tension and irritability are common on lower socio-economic classes; guilty ruminations and self-reproach are more characteristic of depressions in Anglo-Saxon cultures, while mania tends to manifest itself in some Mediterranean and African countries as well as in American blacks.

In an epidemiological study of major depression and bipolar disorder (Weissman et al., 1996) it was found that the lifetime rates for major depression vary widely across countries whereas there is a greater consistency for bipolar disorder. The 10 countries from which data were derived were Canada (specifically Edmonton, Alberta), France, Germany (West), Italy, Korea, Lebanon, New Zealand, Puerto Rico, Taiwan and United States of America. Lifetime rates for major depression ranged from 1.5 cases per 100 adults in the sample from Taiwan to 19.0 in Lebanon (Beirut). The value for Canada was 9.6. The annual rates ranged from 0.8 cases per 100 adults in Taiwan to 5.8 in New Zealand. The value for Canada was 5.2. The mean age of on-set shows less variation (range 24.8 - 34.8 years). In every country, the rates of major depression were higher for women than for men, the female/male ratio varying from 1.6 to 3.0. The value for Canada was 1.9. In 
contrast, there were smaller variations in the lifetime rates of bipolar disorder varying from 0.3 per 100 in Taiwan to 1.5 per 100 in New Zealand. The female/male ratio varied from 0.3 in Korea to 1.2 in USA. The value for Canada was 0.7. Mean age at onset for major depression in the Canadian population was 24.8 years, while bipolar depression started at about 17.1 years of age.

Insomnia and loss of energy occurred in most people with major depression in all countries. Other common symptoms (not universally found, but including Canada in all cases) were thoughts of death, concentration problems and feelings of worthlessness. These people with major depression were at increased risk for co-morbidity with alcohol or drug abuse and anxiety disorders. The study also found that people who were separated or divorced had significantly higher rates of major depression than married people in most countries and the risk was somewhat greater for divorced or separated men than women in all countries except Canada. The differences in rates for major depression across countries suggested to the authors that cultural differences or different risk factors may affect the expression of the disorder.

Although this review focuses on depression, suicide cannot be entirely ignored, since this act is considered to be a symptom or sequel of depression It should also be pointed out that, in the epidemiological studies relating depression to extremely low frequency electromagnetic fields, clinical depression resulting in hospitalisation or pharmacological treatment is seldom mentioned; the studies tend to target depressive symptoms and, often, over a short time frame.

\section{Electromagnetic Fields}

Matter consists of molecules constituted by atoms, which, in turn consist of subatomic particles of many kinds, including electrons and protons. A property of electrons and protons is their equal and opposite electrical charges, negative and positive, respectively. These particles possess the smallest units of electrical charge that can be isolated and all larger charges consist of multiples of their electronic charge. Electrically charged particles exert forces on each other, opposites attracting, while like charges repel. Such forces are described in terms of electrical fields, if the charge is not moving, but if the charge is moving then a magnetic field is also produced. Electric fields are produced, for example, when voltage (difference in potential energy) forces electricity along a wire. The higher the voltage the stronger the field produced. Since the voltage can exist 
even when no current is flowing, an appliance does not have to be turned on for an electric field to exist. However, if the voltage is reduced to zero (by unplugging an appliance) then the electric field disappears. Magnetic fields are created only when an electric current flows; magnetic fields and electric fields then exist together. When the current is greater the magnetic field is stronger. While voltages are stable, currents vary with power consumption, hence the electric field is stable, but the magnetic field fluctuates with power consumption.

Electric fields can be reduced by shielding, particularly by metal, but such fields, from power lines, for example, can also be reduced by walls, buildings and trees. Magnetic fields, on the other hand, pass through most materials, so they are not reduced by burying a power line.

An electric field can be produced also by a changing magnetic field. The mutual interaction of electric and magnetic fields produces an electromagnetic field, which is considered as having its own existence in space apart from the charges or currents with which it may be related. Under certain circumstances, this electromagnetic field can be described as a wave transporting electromagnetic energy.

An electromagnetic wave is produced when a line of charges is moved back and forth along the line. Moving charges represent an electric current. In this back-and-forth motion, the current flows in one direction and then in another. As a consequence of this reversal of current direction, the magnetic field around the current (discovered by Ørsted and Ampère) has to reverse its direction. The time-varying magnetic field produces perpendicular to it a time-varying electric field, as discovered by Faraday (Faraday's law of induction). These time-varying electric and magnetic fields spread out from their source, the oscillating current, are perpendicular to one another, propagate at the speed of light and constitute an electromagnetic wave. The frequency of this wave is that of the oscillating charges in the source.

While important health effects can result from exposure to electromagnetic radiation of short wavelengths, the wavelengths encountered in extremely low frequency range are so large that their contribution to any observed effects can be ignored. The wavelength at $60 \mathrm{~Hz}$ is $5,000 \mathrm{~km}$ (3,000 miles). 
Terms commonly used to describe low frequency ranges are:

\begin{tabular}{|l|l|}
\hline Term & Frequency range \\
\hline Extremely low frequency & $3 \mathrm{~Hz}-3 \mathrm{kHz}$ \\
\hline Power frequency & $50 \mathrm{~Hz}-1000 \mathrm{~Hz}(1 \mathrm{kHz})$ \\
\hline Very low frequency & $3 \mathrm{kHz}-30 \mathrm{kHz}$ \\
\hline Low frequency & $30 \mathrm{kHz}-300 \mathrm{kHz}$ \\
\hline
\end{tabular}

Magnetic flux density is the commonly used measure of the strength of a magnetic field. It is directly proportional to the current flowing in a wire, is at right angles to the direction of the current and its value is inversely proportional to the perpendicular distance from the wire. The primary units of magnetic flux density are the tesla $(\mathrm{T})$ and the gauss $(\mathrm{G})$; one tesla is equal to ten thousand gauss. Commonly encountered secondary units are:

millitesla $(\mathrm{mT})=10^{-3} \mathrm{~T}=10 \mathrm{G}$

microtesla $(\mu \mathrm{T})=10^{-6} \mathrm{~T}=0.01 \mathrm{G}$

milligauss $(\mathrm{mG})=10^{-3} \mathrm{G}$

As an example, the magnetic flux density at a distance of $10 \mathrm{~m}$ from a wire carrying a current of $100 \mathrm{amp}$ is $125 \mathrm{mG}(12,5 \mu \mathrm{T})$. In comparison, the magnetic flux density of the Earth's field is approximately $500 \mathrm{mG}(50 \mu \mathrm{T})$. Unlike the Earth's magnetic field, however, magnetic fields due to power lines alternate at a frequency of 50 or 60 cycles per second (expressed as $50 \mathrm{~Hz}$ or 60 $\mathrm{Hz})$.

In the United Kingdom, electricity is distributed on the National Grid by overhead cables at 275 or400 kV. These are transformed by area stations for towns and cities to $132 \mathrm{kV}$, to $11 \mathrm{kV}$ in rural communities and, finally, by local substations to the domestic voltage of $240 \mathrm{~V}$. The field directly beneath a $400 \mathrm{kV}$ line is, on average, $10 \mathrm{kV} / \mathrm{m}$ reducing to $200-1000 \mathrm{~V} / \mathrm{m}$ at a distance 
of $100 \mathrm{~m}$, while the field beneath a $132 \mathrm{kV}$ line is about $1000-2000 \mathrm{~V} / \mathrm{m}$ reducing to $2-100$ $\mathrm{V} / \mathrm{m}$ at $100 \mathrm{~m}$. These figures may be doubled under certain climatic conditions. There is no legislation in the United Kingdom prohibiting the erection of residential buildings within certain distances of power lines, whereas in the United States the field cannot be greater than $1600 \mathrm{~V} / \mathrm{m}$ and in what was the Soviet Union the field could not be greater than 10,000 V/m (Dowson et al., 1988). Thus, although power lines in the USA carry similar voltages $(345 \mathrm{kV}, 230 \mathrm{kV}, 220 \mathrm{kV}$, $66 \mathrm{kV}$ ) to those in the UK, residential exposure to electromagnetic fields should not reach the high levels that are permissible in the UK.

Epidemiological studies have mainly taken residential and occupational exposure into consideration, when assessing the effects of extremely low frequency electromagnetic fields on human health. Outdoor environments are often considered as low-level areas, but Lindgren et al. (2001) showed that this is not true in a city environment. They mapped the extremely low frequency magnetic flux densities along certain stretches of pavement in central Goteborg, Sweden. About $50 \%$ of the investigated street length showed flux densities of the same order of magnitude $(\geq 0.2 \mu \mathrm{T})$ as those associated with increased risks of cancer in epidemiological studies. The authors concluded that the outdoor exposures in a city environment also should be considered in exposure assessments and risk evaluations. These elevated flux densities are probably due to stray currents. They also found strong magnetic flux densities $(>1.0 \mu \mathrm{T})$ close to ordinary distribution pillars, power substations, shop alarms, and other electrical devices.

\section{Epidemiology}

Epidemiological studies look for an association in a human population between exposure to some factor(s) and a specific health outcome. They are generally observational, as opposed to being experimental, consequently the main difficulties encountered in the design, analysis and interpretation of epidemiological studies centres upon possible distorting influences or bias. Descriptive studies, such as proportional disease incidence or mortality studies, address population-based frequency data on risk factors and outcome, and are subject to the most undetected bias. Analytical studies are of more sophisticated design and test specific hypotheses, while adjusting for bias. They are of two types: case-control studies and cohort studies. Casecontrol studies compare the exposure experiences of groups of people who have the disease in 
question with control groups of people who do not have the disease. Cohort studies compare the disease outcome experiences of two groups of people with levels of exposure. The data for these studies are then interpreted according to widely agreed criteria of causation. These are:

1. Consistency;

2. Strength of association;

3. Temporal sequence;

4. Dose-response relationship;

5. Specificity;

6. Coherence with previous knowledge; and

7. Biological plausibility.

A consistent effect must be seen in several studies in different populations and at different times; no single study can provide definitive evidence for a relationship. The strength of the association (the size of the relative risk) is also important for inference of causality, as is the correct time sequence of exposure and response, and dose-response relationship. Furthermore, the effect should show a specificity following a particular exposure and should be biologically plausible.

\section{Epidemiological studies relating depression to extremely low frequency electromagnetic field flux}

The articles investigating the association between depression and extremely low frequency electromagnetic fields were identified through MEDLINE searches and review of reference lists in publications thereby obtained.

Nine studies have addressed the possible association between exposure to extremely low frequency electromagnetic fields and depression. They are summarised in Table 1. 
Broadbent et al. (1985) studied non-clerical staff of three Central Electricity Generating Board transmission districts in the south west of England and South Wales (CEGB), together with similar staff of the South Wales Electricity Board (SwaEB). The CEGB staff operated and maintained transmission lines running at 132, 275 and $400 \mathrm{kV}$. The SwaEB staff worked on distribution systems running at 11,33, 66 and $132 \mathrm{kV}$. For two weeks before a questionnaire interview, each subject wore an electric field dosimeter strapped to his upper arm. This provided a measure of cumulative exposure of this two-week period. Measurements were, however, subject to variation dependent upon the subject's height, build, clothing, footwear and the precise way in which the armband was worn. For a given subject standing upright, the standard deviation of calibration readings taken under similar conditions was about $20 \%$. Of the 287 subjects included in the analysis, only 28 received exposures above the $6.6 \mathrm{kVm}^{-1} \mathrm{~h}$ threshold of reliable detection. Exposure was also estimated by senior engineers on the basis of exposure records and work histories of the study subjects. These estimates were generally higher than the measured dose exposures. It had been expected that there would have been significant exposure of transmission line staff, but of 166 measurements, only 26 exceeded the detection threshold. The questionnaire consisted of about 150 questions modified, for use in industrial rather than hospitalised populations, from the Middlesex Hospital Questionnaire (Crown \& Crisp, 1966). The questionnaire was known to give higher scores in people assessed as being ill by more thorough medical examination. The performance of this revised questionnaire was checked against a series of patients to ensure that it would behave in a similar way. The questionnaire includes four scores related to the assessment that would be given at medical interview: anxiety, depression, somatic symptoms and symptoms of obsession. No significant correlations with either recorded exposure readings or professional estimates of exposure for six months or 15 years were found for any of the health characteristics assessed, including depression.

Dowson et al. (1988) studied possible effects of living in the proximity of power lines on the frequency of headaches and depression. The study population lived in a group of houses close to overhead power lines carrying $132 \mathrm{kV}$. A control population was selected 3 miles [4.8 km] away from the power lines, which matched as closely as possible the house types of the study group, but where there were no nearby power cables. A questionnaire was hand delivered to 120 houses 
in each area. This questionnaire requested information on age, sex, social status, duration of local residence, details of recurrent diseases, time lost from normal activities due to illness and the stability of health status over the past year. The response rate was $60 \%$, resulting in a study group of 132 and a control group of 94 . The social status of both groups was uniformly class III. Recurrent headache was increased in the range $60-80 \mathrm{~m}$ of the power line, but not closer or further away, while self-reported depression occurred in nine of the study group (seven of whom, in a total of 38 , were living within $40 \mathrm{~m}$ of the power line) and one in the control group. The node of recurrent headache frequency is difficult to explain. With regard to depression, this study did not use a validated scale for the identification of depressive symptoms, but relied upon a selfreported assessment and consequently lacks any standardisation of criteria. Thus, although this is an interesting early report, it serves only to open up the issues and is considered inadequate for evaluation purposes.

Following up work previously published on suicides (Reichmanis et al., 1979; Perry et al., 1981), Perry et al. (1989) studied whether susceptibility to depressive illness of people living in Wolverhampton, U.K. was related to the intensity of $50 \mathrm{~Hz}$ magnetic field outside their homes. Cases were patients discharged from Wolverhampton Hospitals in 1985 with diagnoses of depressive illness (ICD 296 and/or 311) and living within the Metropolitan Borough of Wolverhampton. Controls were selected from the 1985 Electoral Register for the same area. Field strength assessment showed that houses of cases had significantly higher field levels than those measured in houses of controls: $2.26 \mathrm{mG}$ versus $2.07 \mathrm{mG}, \mathrm{p}<0.03$. These control values are considerably higher than those found in the earlier, suicide study by the group and it is questionable whether such a small difference between the field strength values is a plausible explanation for the depressive symptoms. The authors recognised some drawbacks in their study, including the possibility that the distance of a property from the public footpath might be an important variable, because of street noise, pollution and less desirable aspects of the older terraced houses and that the high field strength might be due to the proximity of the front door to the street and possibly to a main underground cable. The issue of confounding, especially by socio-economic factors, was not addressed. In addition, contributions from household electrical appliances were not considered, unlike in their earlier study of suicide, in which they were thought to make a major contribution. 
Poole et al. (1993) conducted a telephone interview survey in November 1987 to assess the prevalence of depressive symptoms and headache in relation to proximity of residence to an alternating-current transmission line in the United States. The target population were residing in eight towns along a transmission line right-of-way in the USA in 1987. The lines consisted of 69 $\mathrm{km}$ of two single-circuit $230 \mathrm{kV}$ lines, which were joined by a single $345 \mathrm{kV}$ line for $3 \mathrm{~km}$ before it continued alone for another $13 \mathrm{~km}$. The potential participants were 705 people drawn from telephone directories covering the study area supplemented by all 205 adults known to reside in houses abutting the right-of-way and all 249 study area residents who, by signing a petition or attendance sheet at a public meeting, had expressed active interest in a new power line proposal. Complete interviews were obtained with 259 adults from the directory sample, 60 adult members from those with an active interest, 53 residing in abutting properties and 10 adults who appeared in both of the latter two groups. The participation rate was $69 \%$, varying from $67-73 \%$ across the groups. The questionnaire sought to elicit from the participants their demographic characteristics, strength of general environmentalist attitudes, perceived impact of environmental exposures on their health, information on depressive symptoms and experience of migraine or non-migraine headaches within the last 7 days. Proximity to the line, which was defined as residing on a property abutting the right-of-way or being able to see the towers from one's house or garden, was positively associated with a measure of depressive symptoms based on the Center for Epidemiologic Studies-Depression scale. An elevated prevalence of scores above the median value was associated with female sex, younger age, less education and disrupted marital status. Depressive symptoms were more prevalent among participants who expressed concerns about transmission lines in relation to their own health. A positive association was found between prevalence of depressive symptoms and the principle measure of residential proximity to the transmission line right-of-way with odds ratio 2.8 (95\% confidence interval (CI) 1.6-5.1). The association became stronger when all potential confounders were controlled for. The estimate did not change appreciably when the definitions of depressive symptoms or of proximity to the line were altered. Non-migraine headaches had a weaker association with proximity to the line (odds ratio $=1.5,95 \%$ CI 0.76-2.8), and self-reported migraine headaches showed no association (odds ratio $=0.99,95 \%$ CI $0.29-3.4)$. This is often regarded as the earliest adequate study providing evidence of an association between exposure to electromagnetic fields and the occurrence of 
depressive symptoms. An important weakness of the study, however, is in the exposure evaluation, whereas its strength is that validated assessments of depressive symptoms were applied.

Savitz et al. (1994) analysed data from the Vietnam Experience Study for a possible association between electromagnetic field exposure and depression. In order to compare the risk of diagnosed depression, depressive symptoms, and elevations in personality scales indicative of depression, employed participants were classified as electrical workers $(\mathrm{N}=183)$ and nonelectrical workers $(\mathrm{N}=3,861)$ and their scores compared on the Diagnostic Interview Survey (DIS) and the Minnesota Multiphasic Personality Inventory (MMPI). The present job alone served as the basis for exposure classification. For 1051 of the 4044 men in the study, the current job was not the longest held. Data were analysed on the lifetime prevalence of depression, prevalence of depression in the month preceding the survey and lifetime prevalence of recurrent unipolar depression. The symptoms of depression analysed from the Diagnostic Interview Survey were: weight loss or gain, sleep disturbance, slowness or restlessness, lack of sexual interest, fatigue, feelings of worthlessness, trouble in concentrating and thoughts of death. Electrical workers were compared with non-electrical workers by age, marital status, education, income, race, alcohol use, rank at discharge from the army, location of army service (Vietnam or other) and years in the current job. A preliminary analysis suggested that duration of employment was related to depression, with the highest risk occurring amongst men who had the briefest employment period. Consequently, all later analyses were stratified by duration of (current) employment into $<10$ years, $11-15$ years and 16+ years. The pattern of results from the Diagnostic Interview Survey showed no clear tendency for electrical workers in aggregate to show elevated risks. Lifetime depression and recurrent unipolar depression were unrelated to electrical occupations, but depression in the month before the survey showed a tendency to be more common amongst electrical workers, which was not, however, statistically significant (odds ratio $=1.7,95 \%$ C.I. $=0.7-4.3$ ). Symptoms of depression in association with job were variable, with trouble concentrating tending to be more common amongst electrical workers, particularly if employed $<10$ years (relative risk $=2.0,95 \%$ C.I. $=0.8-4.9$ ), while weight gain or loss and, particularly, loss of interest in sex tending to be less common amongst electrical workers (odds ratio $=0.2,95 \%$ C.I. $=0.0-1.5)$. Results from the MMPI also showed for electrical workers in 
the aggregate that there was little evidence of increased risk, although there was a consistent pattern of modest elevations in the MMPI depression scores for short-term workers, but none of these was statistically significant. Data on electricians only yielded indications of increased risk for several markers of depression, however the authors noted that this was not the group most certain to have elevated electromagnetic field exposures.. Despite the small number of electrical workers, uncertainty regarding exposure, and the recognised (by the authors) inability to address other workplace exposures, these results suggest that electrical workers in general are not at increased risk for depression.

One of the criticisms of the studies of Dowson et al., 1988 and Savitz et al., 1994 is that they have relied upon the use of surrogate measures of electromagnetic fields. In an effort to overcome this limitation, McMahan et al. (1994) combined the methodologically preferred administration of a standardised measure of depression (the Center for Epidemiological Studies Depression scale) with doorstep measurements of electromagnetic fields. The study was conducted in a predominantly white, upper socio-economic status part of Orange County, CA, USA in 1992. The area was adjacent to an easement (right-of-way, in the UK literature) containing two fourcircuit, $220 \mathrm{kV}$ transmission lines and two $66 \mathrm{kV}$ transmission lines. The participants were 152 women who lived either on the easement or one block away. Interviews were conducted on the door step, with the real purpose being concealed from the women. The interviews covered the respondent's health, life events, family history, health habits, occupation and home life. Magnetic fields were measured using a portable electric and magnetic digital exposure meter (EMDEX-C) that provides a detailed exposure record. The average magnetic field level was 4.86 $\mathrm{mG}(95 \%$ C.I. $=4.26-5.47)(0,49 \mu \mathrm{T})$ at the front door of homes on the easement and $0.68 \mathrm{mG}$ $(95 \%$ C.I. $=0.62-0.75)(0,07 \mu \mathrm{T})$ at the front door of homes one block away. The distribution of Center for Epidemiological Studies Depression scale scores was skewed and did not appear to be consistently associated with residence on or away from the easement. Women living on the easement were no more likely than those living away from the easement to report increased depressive symptoms (odds ratio $=0.94,95 \%$ C.I. $=0.48-1.85$ ). Furthermore, there was no significant difference in Center for Epidemiological Studies Depression scale scores between the groups after controlling for demographic variables. There was a tendency (not statistically significant) for women with longer residence to report fewer depressive symptoms. Ethnicity, age, education and income appeared to be unrelated to depressive symptoms. The authors 
recognised that the homogeneity of the study population (mainly white, all women, most having completed higher education) may limit the generalisation of these findings.

Beale et al. (1997) studied the dose response patterns within a population, all members of which were living near $50 \mathrm{~Hz}$ transmission lines in the Auckland Metropolitan area, New Zealand. Houses on streets running beneath or beside overhead transmission lines were located on topographic maps of the area. Invitations to the residents to participate in the study were left at those houses where gate readings exceeded $0.5 \mu \mathrm{T}$ and others in the same street where the gate readings were less than $0.3 \mu \mathrm{T}$. Five hundred and forty people aged $18-70$ years living in 374 households met all of the inclusion criteria and completed all the questionnaires and tests. Interviews included the administration of five tests of attentional skills, two tests of memory for new material and three questionnaires. Of these, the Life Changes Questionnaire and especially the General Health Questionnaire-28 (GHQ) (Goldberg \& Williams, 1988) had relevance for the assessment of depression. Scores on this scale are strongly correlated with professional diagnosis of psychological disorder. In addition to the total score used for "caseness" identification, four factor scores are derived from independent subsets of the questions. These subsets provide scores for GHQ-somatic, GHQ-anxiety, GHQ-social dysfunction and GHQ-depression. Participants additionally were asked to self-evaluate their health and indicate their ideas on whether living near a power line affected their health.

Field measurements were made at the time of the interview at three places in all rooms within the house in which the participants spent $1 \mathrm{~h}$ or more, on average, each day. As a check for seasonal variations in magnetic fields, 38 of the houses were revisited and field measurements repeated. From these measurements, two exposure estimates were calculated: average exposure and atimeintegrated exposure. On the basis of the latter, study subjects were categorised in to quintiles.

Multiple regression analyses were carried out separately on two data sets: (1) all of the neuropsychological tests and (2) on the self-reported general health and psychological health measures. These analyses included adjustments for age, sex, socio-economic status and life changes. In addition, the effects of self-assessed health status and perceived effects of power lines on health were investigated. Among the neuropsychological test measures, the only category for which the regression coefficient was significant was the Digit-Symbol test (which is 
one of the most sensitive indicators of undifferentiated brain damage). For none of these tests, including the Digit-Symbol test, did adjustment for presumed confounders have any marked effect. Because the Digit-Symbol test was not given special status by any a priori hypotheses, this result was considered by the authors as only weakly supportive of an interpretation that cognitive function is adversely affected by exposure. The regression coefficient for GHQdepression was significant at the 0.05 level, but it lost significance when it was additionally adjusted for the subjects' perception of the effect of power lines on health. This factor led to a $38.5 \%$ reduction in the adjusted regression coefficient for depression; it also reduced the regression coefficients based on somatic and anxiety category scores by $40.5 \%$ and $22.8 \%$, respectively. Thus, time-integrated exposure measurement appears to be a predictor for the occurrence of depressive symptoms in this study, but the association was weak and confined to the highest exposure quintile. The increased score between the lowest and the highest exposure categories, even before adjustments of any kind were made, was only $7.5 \%$ and was apparently dependent upon the perception by the subjects of the effect of power lines on their own health. It is unclear, however, how this modification of the association might have been brought about. . One interpretation is that participants had an implicit awareness of their exposure level and also believed that higher exposure levels had a more detrimental effect than lower exposure levels on health. While the latter is plausible, the former is not, since all of the participants lived near the power lines and probably had little idea of the factors that jointly determine their exposure as individuals to the magnetic fields arising from the lines. It is possible that the adjustment for the perception by the study subjects of the effect of power lines on their health accounted for some unidentified factor that might confound the association between electromagnetic fields and depression.. Verkasalo et al. (1997) used two available nationwide data sets, the Finnish Twin Cohort Study and the Finnish Transmission Line Study, to investigate the contribution of magnetic fields to depression. The Finnish Twin Cohort Study is an epidemiological project designed to study genetic and environmental determinants of chronic disease. The part of the cohort used in this study of transmission lines and depression was compiled from the Central Population Registry of Finnish citizens in 1974. It consists of all same-sex pairs born before 1958 with both members alive in 1967 . Twins were mailed a questionnaire in 1975 and $89 \%$ responded. In a follow-up of the twins, a questionnaire was sent in 1990 to those born between 1930 and 1957 with both members alive in 1987 . The response rate was $77.5 \%$, representing 
12,063 people (5,512 men and 6,551 women) who had answered the 21-item Beck Depression Inventory of self-rated depressive symptoms. The personal 20-year histories of exposure (i.e., distance and calculated annual average magnetic fields) before 1990 to overhead 110- to 400-kV power lines and magnetic fields calculated to be $\geq 0.01 \mu \mathrm{T}$ were obtained from the Finnish Transmission Line Cohort Study. The reported mean Beck Depression Inventory scores for the exposure subgroups of interest were adjusted for a battery of covariates: i.e., sex, social class, education, marital status, working outside the home, regular day work, engagement in salary work, current smoking, presence of heavy drinking, number of alcohol-related pass-outs during the past year, life events scale and social support scales. These adjusted mean Beck Depression Inventory scores did not differ by exposure, providing some assurance that proximity to highvoltage transmission lines is not associated with changes within the common range of depressive symptoms. These data are show below:

\begin{tabular}{|c|c|c|c|c|c|}
\hline & \multicolumn{5}{|c|}{$\begin{array}{c}\text { Beck Depression Inventory Scores for People Living near Transmission } \\
\text { Lines (distance in 1989) }\end{array}$} \\
\hline & $\geq 500 \mathrm{~m}$ & $200-500 \mathrm{~m}$ & 100-199 m & $50-99 \mathrm{~m}$ & $<50 \mathrm{~m}$ \\
\hline All subjects & 5.30 & 5.27 & 4.95 & 5.08 & 4.20 \\
\hline Men & 4.61 & 4.91 & 4.68 & 4.04 & 4.53 \\
\hline Women & 5.86 & 5.50 & 5.19 & 6.03 & 3.47 \\
\hline
\end{tabular}

However, the risk of severe depression was increased 4.7-fold (95\% C.I. $=1.70-13.3)$ amongst subjects living within $100 \mathrm{~m}$ of a high-voltage power line. This finding was based on only four women (3 dizygous, 1 monozygous, ages 30-60 years). No other characteristics of these people were available from the publication. Also, only one, the 60 year-old woman, lived in the range $<$ $50 \mathrm{~m}$ from a power line. Limitations of the study concern exposure estimates and exposure misclassification. Thus, the authors point out that there were relatively low levels of power linegenerated magnetic field exposures. Baseline levels at typical Finnish homes rarely exceed 0.1 
$\mu \mathrm{T}$, whereas the working day average magnetic fields are $0.17 \mu \mathrm{T}$ at the $50^{\text {th }}$ percentile and 0.27 $\mu \mathrm{T}$ at the $75^{\text {th }}$ percentile. Verkasalo et al.(1997) controlled for three strong determinants of major depression, namely, stressful life events, genetic factors and a previous history of major depression, but none of these explain the results obtained in this study. Personality trait of neuroticism was not controlled for and neither were other determinants, such as somatic diseases, medicines or visible light. Conclusions to be drawn from this study are: (1) residing in magnetic fields of $50 \mathrm{~Hz}$ near power lines is not associated with changes in the occurrence of depressive symptoms; (2) the case for more severe depression is unclear. A risk increase was observed for severe depression, but there was a very small number of cases and the magnetic fields were scarcely increased.

The most recent study (Bonhomme-Faivre et al., 1998) of psychological symptoms and extremely low frequency electromagnetic fields is a survey conducted in France on a group of 13 people exposed occupationally to electromagnetic fields and a control group of 13 subjects. The exposed group worked at least $8 \mathrm{~h}$ /day for $1-5$ years in a laboratory located above transformers and high-tension cables and in adjacent offices. The control group was matched for age, sex and socioeconomic status and worked on the same site, but in areas that were not situated in the immediate vicinity of transformers and high-tension cables.. The electromagnetic fields in the offices adjacent to the laboratory were $0.2-0.3 \mu \mathrm{T}$ at floor level and $0.09-0.12 \mu \mathrm{T}$ at $1.50 \mathrm{~m}$ above floor level, while, in the laboratory, the corresponding values were $1.2-6.6 \mu \mathrm{T}$ and $0.3-$ $1.5 \mu \mathrm{T}$. Participants were asked to complete a self-rating questionnaire that did not appear, however, to have been validated. The exposed group had significant increases in degree of certain characteristics, namely physical fatigue, psychical asthenia (weakness), lipothymia (feeling of faintness), decreased libido, melancholia, depressive tendency and irritability. In this small study, all subjective disorders (i.e., answers to 28 questions) other than headache were elevated in the exposed group, and it is possible that the participants were aware of the purpose of the study. 


\section{Related epidemiological studies}

A consideration in the evaluation of all the studies summarised above is whether human populations living near power lines have special characteristics and whether the act of residing in these artificial landscapes - with or without the physical generation of particular health outcomes - can engender feelings of concern. Few studies have documented public perceptions of environmental health risks from exposure to overhead transmission lines. In particular, little information has been provided on the impact of worry on symptom prevalence in residents living adjacent to high voltage transmission lines.

A study by McMahan \& Meyer (1995) assessed symptom prevalence and worry in 152 Orange County women living either adjacent to overhead transmission lines or one block away. The location, participants and magnetic field flux measurements were the same as in the study (McMahan et al.,1994) described above. Forty-five percent of the respondents were either very worried or somewhat worried about the transmission lines and 55\% were slightly worried or not worried at all. Results indicated that for those who did not live on the easement level of worry did not affect the prevalence of health problems. Residents on the easement were no more likely than those who lived one block away to report any supposed electromagnetic field-related health problems (headaches, migraines, poor appetite and difficulty in sleeping, concentrating or getting going) (odds ratio $=0.85$, C.I. $=0.45-1.62$ ). Level of worry, however, did impact on the prevalence of supposed electromagnetic field-related health problems. For those who lived on the easement, the most worried respondents were more likely to report health problems:

\begin{tabular}{|l|c|c|c|c|}
\hline & \multicolumn{2}{|c|}{ Not living on the easement } & \multicolumn{2}{c|}{ Living on the easement } \\
\hline & Not worried & Worried & Not worried & Worried \\
\hline No problems & $41 \%, \mathrm{n}=19$ & $37 \%, \mathrm{n}=11$ & $61 \%, \mathrm{n}=23$ & $27 \%, \mathrm{n}=10$ \\
\hline$\geq$ One problem & $59 \%, \mathrm{n}=27$ & $63 \%, \mathrm{n}=19$ & $40 \%, \mathrm{n}=15$ & $74 \%, \mathrm{n}=28$ \\
\hline & & & & \\
\hline & $\mathrm{OR}=1.21,95 \%$ C.I. $=0.47-3.13$ & $\mathrm{OR}=4.30,95 \%$ C.I. $=1.62-11.35$ \\
\hline
\end{tabular}


Most of the women (38\%) said they were disturbed by magnetic fields, $11 \%$ by the noise, $11 \%$ by the aesthetics, $6 \%$ by potential shocks and $9 \%$ said all of the above factors disturbed them; $5 \%$ were disturbed by other factors and 19\% were undisturbed by the power lines.Disclosure of health problems may depend more on an individuals' level of worry about rather than proximity to overhead transmission lines. Possible limitations of this study include personality variables such as hypochondriasis (which were not assessed), recall bias, and social desirability. The homogeneity of the study population may also limit the generalisation of these findings.

Populations living close to high-voltage transmission lines often have residential magnetic field exposures in excess of $1 \mu \mathrm{T}$, and sometimes over $2 \mu \mathrm{T}$. Yet, populations studied in most epidemiological investigations of the association between residential magnetic field exposure and depression typically have exposures below $1 \mu \mathrm{T}$ and frequently below $0.5 \mu \mathrm{T}$. To improve statistical power and precision, it would be useful to compare high exposure populations with low exposure populations rather than only studying small differences within low exposure populations. Toward this end, Wartenberg et al. (1993) developed an automated method for identifying populations living near high-voltage transmission lines. These populations are likely to have more highly exposed individuals than the population at large. The method used a geographic information system to superimpose digitalized transmission line locations on U.S.A. Census block location data and then extract relevant demographic data. Analysis of data from a pilot study of the populations residing within $100 \mathrm{~m}$ of a $29-\mathrm{km}$ segment of one $230-\mathrm{kV}$ line in New Jersey showed that when compared to populations in the surrounding census blocks farther than $100 \mathrm{~m}$ from this line, those populations close to the line have similar demographics but differ in terms of perceived housing value variables.

Although suicide has not been or intended to be reviewed in any detail here, depression causes over half of all attempted suicides and so total neglect of this act might be viewed as a gap in this review. Therefore, some space will be given to this subject, for which there is a pattern in the publications similar to that found in the depression literature. The publications have been reviewed by Ahlbom (2001). Thus, the first study, based on 589 suicide cases and controls in England, found higher fields at the homes of cases than of controls (Reichmanis et al., 1979; Perry et al., 1981), but the study has been criticised for the way that subjects were selected and for the method of statistical analysis. Five subsequent studies are of much better quality and four 
of these provide no support for the conclusion of the earlier one. Two of these studies suffered from having only crude estimates of exposure (McDowall, 1986; Baris \& Armstrong, 1990), but two later studies (Baris et al., 1996a, 1996b; Johansen \& Olsen, 1998) were based on cohorts of power utility workers established specifically for the purpose of studying electromagnetic fields and these used relatively good exposure assessments and follow-up procedures. The remaining and most recent study (van Wijngaarden et al., 2000) consisted of a case-control study of 536 deaths from suicide nested in a cohort of 138,905 male electric utility workers. This provides some evidence for an association between occupational electromagnetic fields and suicide, especially among workers aged less than 50 years. A limitation of this study, however, was an inability to control for the main known risk factors for suicide, namely drug use, mental illness and family and social stresses.

\section{Biological plausibility: possible mechanisms}

The highest voltage gradient that can be created across a cell membrane by a $60 \mathrm{~Hz}$ field as normally encountered in daily life (from fields of $1-5 \mathrm{G}(0,1-0,5 \mathrm{mT})$, created by hairdryers or electric shavers) is in the order of tens of volts/meter. In comparison, the natural gradient across cell membranes is about $10^{7} \mathrm{~V} / \mathrm{m}$. This has been the basis for the scepticism meeting any suggestion of a biological effect (let alone a pathological effect) of extremely low frequency electromagnetic fields. A useful review of proposed mechanisms has been provided by Wood (1993).

Sixty-Hz fields have been found to have an effect on calcium ion efflux across brain tissue cell membranes. Bawin \& Adey (1976) found that, in chick brain tissue, calcium efflux decreased with exposure to the electromagnetic field, whereas Blackman et al. (1982) found calcium efflux to increase, using the same type of tissue preparation. These responses from chicken brain appeared to be quite elusive, particular combinations of frequency and intensity being required for the observation. The effect of exposure to a $60 \mathrm{~Hz}$ field is not clarified by the finding that, in chick spinal cord, Gunderson et al. (1986) could find no calcium efflux.

Studies on rats have demonstrated a depression in night-time melatonin production (Wilson et al., 1983; Reiter et al., 1988) and this observation has led to a hypothesis for a mode of biological action by electromagnetic fields. 
Melatonin, a hormone secreted by the pineal gland, in the brain, is secreted in a circadian pattern with high levels at night and low levels during the day. The circadian release of melatonin is known to influence certain physiological functions and to modulate the release of other hormones. Low levels of melatonin at night have been observed in depressed patients (Wetterberg, 1997), but it remains unclear if they are the cause or merely a consequence of depression. A critical aspect of establishing the relevance and validity of such suggestions would be to determine if melatonin is suppressed during or after exposure to extremely low frequency electromagnetic fields.

Studies evaluating human endocrine function after exposure to 50 or $60 \mathrm{~Hz}$ magnetic fields under laboratory conditions have been conducted in four laboratories. Results have been principally negative with respect to observing effects during exposure. Night time exposure of volunteers to fields under controlled exposure and lighting conditions had no apparent effect on nocturnal blood concentrations of melatonin when compared to sham-exposed subjects (Graham et al., 1996; Akerstedt et al., 1999; Selmaoui et al., 1997; Wood et al., 1998).

A heterogeneous group of studies have also evaluated human endocrine function after exposure to extremely low frequency electromagnetic fields in the relatively uncontrolled environment of occupational and residential epidemiological studies. Unlike the negative results of laboratory investigations, some perturbation in the excretion of 6-hydroxy-melatonin sulfate (the stable, primary metabolite of melatonin) was observed in exposed groups in all of the reported studies. The perturbations were not, however, consistent across studies. The exposure parameters also differed from one study to another and included the use of electric blankets (Wilson et al., 1990) and $16.7 \mathrm{~Hz}$ fields in railway engineers Pfluger \& Minder, 1996) as well as $60 \mathrm{~Hz}$ residential (Davis et al., 2001 in press) and 50 and $60 \mathrm{~Hz}$ occupational exposures (Burch et al., 1998, 2000; Juutilainen et al., 2000).

\section{Discussion and Conclusions}

The epidemiological studies that have addressed the relationship between exposure to extremely low frequency electromagnetic fields and the occurrence of depressive symptoms or depression have faced particular difficulties with exposure assessment, the reliable identification of symptoms and control for confounding factors. These elements need to be addressed in any 
epidemiological study, but there have been - and continue to be - particular difficulties for this topic.

In the studies of Dowson et al. (1988) and Poole et al. (1993), exposure was equated to residing at a particular distance from an overhead power line, there being no direct measurements made.

Savitz et al. (1994) relied upon job classification as a surrogate for exposure. Measurements were made at the front door of the dwellings of the participants in the Perry et al. (1989) and McMahan et al. (1994) studies, but there were problems with the measurements made in the former study. Thus, Perry et al. (1989) report high average electromagnetic field levels for the "non-exposed" group that have not been explained and it seems unlikely that the effects reported in the "exposed" group could be due to the very small difference in the field measurements (i.e., $2.3 \mathrm{mG}$ $(0,23 \mu \mathrm{T})$ for the exposed group and $2.1 \mathrm{mG}(0,21 \mu \mathrm{T})$ for the non-exposed group). The study of Broadbent et al. (1985) attempted to make an accumulative measurement of occupational exposure during a two-week period, but the measurements were unexpectedly low and only reached the level of reliable detection in a very small proportion of the subjects. Inclusion of one of the work categories (transmission line staff) led to the expectation that many more would have been significantly exposed. Another attempt to obtain an exposure estimate more representative than a single measurement was that of Beale et al. (1997). A time-integrated figure was obtained for rooms in the households (in the vicinity of power lines) of the subjects. In the study of Bonhomme-Faivre et al. (1998), direct measurements were made on several occasions that permitted the calculation of an average weekly occupational exposure. In this study, however, no assessment of the exposure of the control population was reported. In the Verkasalo et al. (1997) study, exposures of the individuals were calculations based upon typical locations of phase conductors in power lines and distance. These calculations gave low exposure estimates for the sites of the dwellings. Furthermore, in all studies, contributions from non-residential or nonoccupational sources of extremely low frequency electromagnetic fields and exposures from other sources within the dwellings were not considered, although these can be substantial. Thus, no study was able to take account of magnetic field flux as a time-dependent vector quantity and since there is a variety of magnetic field sources, exposure assessments should ideally take these numerous components into consideration. Non-differential exposure misclassification would, however, tend to bias the risk estimates towards unity, thereby decreasing the possibility of observing differences between groups 
The studies of Dowson et al. (1988) and Bonhomme-Faivre et al. (1998) suffer from not using validated scales for the identification of depressive symptoms. In the case of Perry et al. (1989), although no validated depression scale was applied, the cases were depressive patients who had been discharged from hospitals in a particular area, i.e., they had been clinically diagnosed with depression and treated for the condition. Modified or adapted general health questionnaires, including scores for somatic, social dysfunction, anxiety and depression categories that were used were the Middlesex Hospital Questionnaire (Broadbent et al., 1985) and both the Life Changes Questionnaire and the General Health Questionnaire-28 (Beale et al., 1997) Validated depression scales were used in the remaining fourstudies. These were the Beck Depression Inventory (Verlasalo et al., 1997), the Center for Epidemiological Studies Depression scale (McMahan et al., 1994; Poole et al., 1993), and both the Diagnostic Interview Survey and the Minnesota Multiphasic Personality Inventory (Savitz et al., 1994). Of these studies, Poole et al. (1993) compared subjects on properties abutting a power line right of way with subjects living further away and found a relative risk of 2.8 (95\% C.L. 1.6 - 5.1), while McMahan et al. (1994) using a somewhat similar study design and measurements showing considerably higher electromagnetic field levels near the lines than in properties further away found a relative risk of 0.9 (95\% C.I. 0.5 - 1.9). The study of Savitz et al. (1994) was based on occupational exposure and found no association for electrical workers in aggregate although there were some indications of an association for specific jobs. Finally, Verkasalo et al (1997) combined a depression scale with data on residential magnetic fields applied to the Finnish Twin Registry and found no overall relation between estimated electromagnetic field levels and the Beck Depression Inventory score. They did, however, find a clear excess of severe depression among those living within $100 \mathrm{~m}$ of transmission lines, although this conclusion was based on very small numbers $(n=4)$.

In the more robust studies (Poole et al., 1993; McMahan et al., 1994; Savitz et al., 1994; Beale et al., 1997, Verkasalo et al., 1997) there has been adjustment for several demographic factors, social class and, in some cases, factors that are common risk factors for depression or the emergence of depressive symptoms (see Table 1). Of particular importance is adjustment for social class as this has been related to increased incidence of depression and may be related to exposure, e.g., a type of neighbourhood or dwelling. In no study, however, has there been mention of adjustment for exposure to exogenous steroid hormones in women. The extent to which such adjustments were made is not always clear and some of the studies suffer to a greater 
or lesser extent from a lack of consideration of some of these confounding factors (see pages 2-3, above). It is well established that confounding may distort the observed relationship between exposure and disease, either attenuating or increasing the observed effect. An additional problem with adjusting for confounders in the studies described here is that most of them have small total numbers in the higher exposure categories, thereby making estimates unstable even before applying adjustments for various factors. Therefore, any conclusions reached on the basis of currently available information must be tentative in view of these limitations on both exposure assessment and consideration of bias and confounding in the study populations.

In conclusion, although the studies of Dowson et al.(1988), Perry et al. (1989) and BonhommeFaivre et al. (1998) might be considered to be particularly troubled by various difficulties and, therefore, should be given less weight, the same cannot be said of the Poole et al. (1993) study, in which an increased risk was found. Since, however, the remaining five valid studies (Broadbent et al., 1985; Savitz et al., 1994; McMahan et al., 1994; Beale et al., 1997; Verkasalo et al., 1997) are mainly null, there is only weak evidence supporting an hypothesis of an increase in depressive symptoms occurring as a result of exposure to electromagnetic fields. If one includes suicide as an extreme response to depression, then the conclusion is similar. The present situation is, therefore, that the larger proportion of acceptable studies does not show a relation of exposure to electromagnetic fields with the health effect in question. Finally, the current status of research on plausible biological mechanisms, including a role for melantonin, does not provide strong support for the hypothesis that exposure to extremely low frequency electromagnetic fields is a risk factor in the development of depressive symptoms. 


\section{References}

Ahlbom, A. (2001) Neurodegenrative diseases, suicide and depressive symptoms in relation to EMF. Bioelectromagnetics Suppl., 5, S132-S143.

Akerstedt, T., Arnetz, B., Ficca, G., Paulsson, L.-E. \& Kallner, A. (1999) A 50-Hz electromagnetic field impairs sleep. J. Sleep Res., 8, 77-81.

American Psychiatric Association (1980). Diagnostic and Statistical Manual of Mental Disorders, Third Edition. Washington DC. American Psychiatric Association.

Asanova, T.P. \& Rakov, A.I. (1972) The state of health of persons working in the electric field of outdoor $400 \mathrm{kV}$ and $500 \mathrm{kV}$ switchyard. Piskataway, NJ: Inst.Electric.Electron.Engin. Power Engineering Soc., Special Pub.No. 10.

Baris, D. \& Armstrong, B. (1990) Suicide among electric utility workers in England and Wales. Brit.J.Ind.Med., 47, 788-792

Baris, D., Armstrong, B.G., Deadman, J. \& Thériault, G. (1996a) A case cohort study of suicide in relation to exposure to electric and magnetic fields among electrical utility workers.

Occup.Environ.Med., 53, 17-24.

Baris, D., Armstrong, B.G., Deadman, J. \& Thériault, G. (1996b) A mortality study of electrical utility workers in Québec. Occup.Environ.Med., 53, 25-31.

Bawin, S.M. \& Adey, W.R. (1976) Sensitivity of calcium binding cerebral tissue to weak environmental electrical fields oscillating at low frequency. Proc. Natl. Acad. Sci. USA, 73, 1999-2003.

Beale, I.L., Pearce, N.E., Conroy, D.M., Henning, M.A. \& Murrell, K.A. (1997) Psychological effects of chronic exposure to $50 \mathrm{~Hz}$ magnetic fields in humans living near extra-high-voltage transmission lines. Bioelectromagnetics, 18, 584-594.

Blackman, C.F., Benane, S.G., Kinney, L.S., Joines, W.T. \& House, D.E. (1982). Effects of ELF fields on calcium-ion efflux. Radiat. Res., 92, 510-520.

Bonhomme-Faivre, L., Marion, S., Bezie, Y., Auclair, H., Fredi, G. \& Hommeau, C. (1998) Study of human neurovegetative and hematologic effects of environmental low-frequency (50$\mathrm{Hz}$ ) electromagnetic fields produced by transformers. Arch. Environ. Health, 53, 87-92.

Broadbent, D.E., Broadbent, M.H.P., Male, J.C. \& Jones, M.R.L. (1985) Health of workers exposed to electric fields. Brit. J.Ind.Med., 42, 75-84.

Burch, J.B., Reif, J.S., Yost, M.G., Keefe, T.J. \& Pitrat, C.A. (1998) Nocturnal excretion of a urinary melatonin metabolite among electric utility workers. Scand. J. Environ. Health, 24, 183189. 
Burch, J.B., Reif, J.S., Noonan, C.W. \& Yost, M.G. (2000) Meltonin metabolite levels in workers exposed to $60-\mathrm{Hz}$ magnetic fields: work in substations and with 3-phase conductors. J. Occup. Environ. Med., 42, 136-142.

Crown, S. \& Crisp, A.H. (1966) A short clinical diagnostic self-rating scale for psycho-neurotic patients. Br. J. Psychiatry, 112, 917-923.

Davis, S., Kaune, W.T., Mirick, D.K., Chu Chen, M.S. \& Stevens, R.G. (2001). Residential magnetic fields, light-at-night, and nocturnal urinary 6-hydroxymelatonin in women.

Am.J.Epidemiol., (in press).

Dowson, D.I., Lewith, G.T., Cambell, M., Mullee, M.A. \& Brewster, L.A. (1988) Overhead highvoltage cables and recurrent headache and depressions. The Practioner, 232, 435-436.

Goldberg, D. \& Williams, C. (1988). A user's guide to the General Health Questionnaire. Berkshire: NFER Nelson.

Graham, C., Cook, M.R., Riffle, D.W., Gerkovich, M.M. \& Cohen, H.D. (1996) Nocturnal metaonin levels in huma volunteers exposed to intermittent $60 \mathrm{~Hz}$ magnetic fields.

Bioelectromagnetics, 17, 263-273.

Gunderson, R., Greenebaum, B. \& Goodman, E. (1986) Effects of 60-Hz electromagnetic fields on calcium efflux and neurotransmitter release. Tech. Rept. for the New York State Power Lines Project.

Imaida, K; Hagiwara, A; Yoshino, H; Tamano, S; Sano, M; Futakuchi, M; Ogawa, K; Asamoto, M; Shirai, T (2000) Inhibitory effects of low doses of melatonin on induction of preneoplastic liver lesions in a medium-term liver bioassay in F344 rats: relation to the influence of electromagnetic near field exposure Cancer Lett., 155, 105-114

Johansen, C. \& Olsen, J.H. (1998) Mortality from amyotrophic lateral sclerosis, other chronic disorders, and electric shocks among utility workers. Am.J.Epidemiol., 148, 362-368.

Juuttilainen, J., Stevens, R.G., Anderson, L.E., Hansen, N.H., Kilpelainen, M., Kumlin, T., Laitinen, J.T., Sobel, E. \& Wilson, B.W. (2000) Nocturnal 6-hydroxymelatonin sulfate excretion in female workers exposed to magnetic fields. J. Pineal Res., 28, 97-104.

Knave, B., Gamberale, F., Bergstrom, S., Birke, E., Iregren, A., Kolmodin-Hedman, B. \& Wennberg, A. (1979) Long-term exposure to electric fields - a cross-sectional epidemiological investigation of occupationally exposed workers in high-voltage substations. Scand.J.Work Environ,Health, 5, 115-125.

Lindgren, M. Gustavsson, M., Hamnerius, Y. \& Galt, S. (2001) ELF magnetic fields in a city environment Bioelectromagnetics, 22, 87-90.

McDowall, M.E. (1986) Mortality of persons resident in the vicinity of electricity transmission facilities. Br.J.Cancer, 53, 271-279. 
McMahan, S., Ericson, J. \& Meyer, J. (1994) Depressive symptomatology in women and residential proximity to high-voltage transmission lines. Am.J.Epidemiol., 139, 58-63.

McMahan, S. \& Meyer, J. (1995) Symptom prevalence and worry about high voltage transmission lines. Environ.Res., 70, 114-118.

Paneth, N. (1993) Neurobehavioral effects of power frequency electromagnetic fields. Environ. Health Pers.101, Suppl. 4, 101-106.

Perry, F.S., Reichmanis, M., Marino, A.A. \& Becker, R.O. (1981) Environmental power frequency magnetic fields and suicide. Health Phys., 41, 267-277.

Perry, S., Pearl, L. \& Binns, R. (1989) Power frequency magnetic field; depressive illness and myocardial infarction. Pub Health, 103, 177-180.

Pfluger, D.H. \& Minder, C.E. (1996) Effects of exposure to $16.7 \mathrm{~Hz}$ magnetic fields on urinary 6hydroxymelatonin sulfate excretion of Swiss railway workers. J. Pineal Res., 21, 91-100.

Poole, C., Kavet, R., Funch, D.P., Donelan, K., Charry, J.M. \& Dreyer, N.A. (1993) Depressive symptoms and headaches in relation to proximity of residence to an alternating-current transmission line right-of-way. Am.J.Epidemiol., 137, 318-330.

Reichmanis, M., Perry, F.S., Marin, A.A. \& Becker, R.O. (1979) Relationship between suicide and the electromagnetic field of overhead power lines. Physiol.Chem.Phys., 11, 395-404.

Reiter, R.J., Anderson, L.E., Buschbom, R.L. \& Wilson, B.W. (1988) Reduction in the nocturnal rise in pineal melatonin levels in rats exposed to $60-\mathrm{Hz}$ electric fields in utero and for 23 days after birth. Life Sci., 42, 2203-2206.

Savitz, D.A., Boyle, C.A. \& Holmgreen, P. (1994) Prevalence of depression among electrical workers. Am J Ind Med. 25, 165-176.

Selmaoui, B., Lambrozo, J. \& Touitou, Y. (1996) Magnetic fields and pineal function in humans: evaluation of nocturnal acute exposure to extremely low frequency magnetic fields on serum melatonin and urinary 6-sulfatoxymelatonin circadian rhythms. Life Sci., 58, 1539-1549.

Verkasalo PK, Kaprio J, Varjonen J, Romanov K, Heikkila K, Koskenvuo M (1997) Magnetic fields of transmission lines and depression. Am J Epidemiol ,146, 1037-1045

Vyalov, A.M. (1967) Physiological and hygienic assessment of labour conditions at 400-500 kV outdoor switchyards. Piskataway, NJ: Inst.Electric.Electron.Engin. Power Engineering Soc., Special Pub.No. 10.

Wartenberg, D., Greenberg, M. \& Lathrop, R. (1993) Identification and characterization of populations living near high-voltage transmission lines: a pilot study. Environ. Health Pers., 101, 626-632. 
Weissman, M.M., Bland, R.C., Canino, G.J., Faravelli, C., Greenwald, S., Hwu, H.-G, Joyce, P.R., Karam, E.G., Lee, C.-K., Lellouch, J., Lépine, J.-P., Newman, S.C., Rubio-Stipec, M., Wells, J.E., Wickramaratne, P.J., Wittchen, H.-U. \& Yeh, E.-K. (1996) Cross-national epidemiology of major depression and bipolar disorder. JAMA, 276, 293-299.

Wertheimer, N. \& Leeper, E. (1979) Electrical wiring configurations and childhood cancer. Am.J.Epidemiol., 109, 273-284.

Wetterberg, L. (1997). Light and melatonin in humans. In, Stevens, R.G., Eilson, B.W. \& Anderson, L.E. (Eds.) The melatonin hypothesis, Battelle Press, Columbus, OH, USA, pp 233265.

Wilson, B.W. (1988) Chronic exposure to ELF fields may induce depression.

Bioelectromagnetics, 9, 195-205.

Wilson, B.W, Anderson, L.E., Hilton, D.I. \& Phillips, R.D. (1983) Chronic exposure to 60-Hz electric fields: effect on pineal function in the rat. Bioelectromagnetics, 2, 371-380.

Wilson, B.W., Wright, C.W., Morris, J.E., Buschbom, R.L., Brown, D.P., Miller, D.L., SommersFlannigan, R. \& Anderson, L.E. (1990) Evidence for an effect of ELF electromagnetic fields on human pineal gland function. J. Pineal Res., 9, 259-269.

van Wijngaarden, E., Savitz, D.A., Kleckner, R.C., Cai, J. \& Loomis, D. (2000) Exposure to electromagnetic fields and suicide among electric utility workers: a nested case-control study. Western J. Med., 173, 94-100

Wood, A.W. (1993) Possible health effects of 50/60 Hz electric and magnetic fields: review of proposed mechanisms. Austral. Physic. Eng. Sci. Med., 16, 1-21.

Wood, A.W., Armstrong, S.M., Sait, M.L., Devine, L. \& Martin, M.J. (1998). Changes in human plasma melatonin profiles in response to $50 \mathrm{~Hz}$ magnetic field exposure. J. Pineal Res., 25, 116127. 


\section{*Table 1. Summary characteristics and results of studies on the relation between EMF and depression.}

\begin{tabular}{|c|c|c|c|c|c|}
\hline Reference & Study Base \& Subject Identification & Exposure & Numbers & RR (95\% C.L.) & Adjustments \\
\hline $\begin{array}{l}\text { Broadbent et al., } 1984 \\
\text { England and Wales } \\
\text { Cross-sectional }\end{array}$ & $\begin{array}{l}\text { Workers operating and maintaining transmission } \\
\text { lines and substations running at } 11,33,66,132,275 \\
\text { and } 400 \mathrm{kV} \text { from } 4 \text { Electricity Generating Board } \\
\text { Districts. } \\
\text { Questionnaire was a modified } \mathrm{MHQ}^{\wedge} \text {, including } \\
\text { questions about depression, anxiety, symptoms of } \\
\text { obsession and somatic symptoms. } \\
90 \% \text { response rate }\end{array}$ & $\begin{array}{l}\text { Miniature Deno dosimeters worn on } \\
\text { the upper arm for } 2 \text { weeks } \\
\text { (integrated exposure) and estimated } \\
\text { exposure } \\
\text { Dosimeter reading above } 6.6 \mathrm{kVm}^{-1} \\
\text { considered as exposed }\end{array}$ & $\begin{array}{l}28 \text { exposed } \\
259 \text { unexposed }\end{array}$ & \multicolumn{2}{|c|}{$\begin{array}{l}\text { No correlation of depression, anxiety, symptoms of } \\
\text { obsession or somatic symptoms with integrated or } \\
\text { estimated exposure (for } 6 \text { months and } 15 \text { years before } \\
\text { the study separately) in the whole population or in the } \\
\text { exposed group only. }\end{array}$} \\
\hline $\begin{array}{l}\text { Dowson et al., } 1988 \\
\text { England } \\
\text { Cross-sectional }\end{array}$ & $\begin{array}{l}\text { People who lived near } 132 \mathrm{kV} \text { line and people who } \\
\text { lived } 3 \text { miles }[4.8 \mathrm{~km}] \text { away. } \\
\text { Questionnaire asking about depression. } \\
60 \% \text { response rate }\end{array}$ & $\begin{array}{l}\text { Distance between home and } \\
\text { overhead line }\end{array}$ & $\begin{array}{l}132 \text { near line; } \\
94 \text { away from line }\end{array}$ & $\begin{array}{l}\text { Strong association of } \\
\text { depression with proximity } \\
\text { to overhead line. } 9 / 132 \\
\text { vs. } 1 / 94\end{array}$ & \\
\hline $\begin{array}{l}\text { Perry et al., } 1989 \\
\text { England } \\
\text { Case-control }\end{array}$ & $\begin{array}{l}\text { People discharged with depression from hospital in } \\
\text { England; controls from electoral list }\end{array}$ & $\begin{array}{l}\text { Measurements at front doors. } \\
\text { Average measurement } 2.3 \mathrm{mG} \text { in } \\
\text { cases \& } 2.1 \mathrm{mG} \text { in controls }\end{array}$ & $\begin{array}{l}356 \text { discharged } \\
\text { patients; } \\
356 \text { controls }\end{array}$ & $\begin{array}{l}\text { Significant regression } \\
\text { coefficient for cases }(P< \\
0.03) \text {, one sided test }\end{array}$ & $\begin{array}{l}\text { Ward, distance, time of } \\
\text { day }\end{array}$ \\
\hline $\begin{array}{l}\text { Poole et al., } 1993 \\
\text { USA } \\
\text { Cross-sectional }\end{array}$ & $\begin{array}{l}\text { A sample of residents in } 8 \text { towns along a transmission } \\
\text { line right-of -way was interviewed } \\
\text { Depressive symptoms were obtained by CES-D* } \\
\text { scale. } 69 \% \text { response rate. }\end{array}$ & $\begin{array}{l}\text { Distance from power line: near vs. } \\
\text { Far. } \\
\text { Near: properties abutting row or } \\
\text { from which towers are visible }\end{array}$ & $\begin{array}{l}88 \text { near the line; } \\
291 \text { away from the } \\
\text { line }\end{array}$ & $2.8(1.6-5.1)$ & $\begin{array}{l}\text { Age, sex, education, } \\
\text { marital status, attitude } \\
\& \text { opinion measures. }\end{array}$ \\
\hline $\begin{array}{l}\text { Savitz et al., } 1994 \\
\text { USA } \\
\text { Cross-sectional }\end{array}$ & $\begin{array}{l}\text { Male veterans who served in the US army first time } \\
65-71 . \\
\text { Two diagnostic inventories were used: the Diagnostic } \\
\text { Interview Schedule and the Minnesota Personality } \\
\text { Inventory } \\
60 \% \text { response rate }\end{array}$ & $\begin{array}{l}\text { Present job as electrical worker } \\
\text { served as basis for exposure } \\
\text { classification } \\
\text { Duration of occupation }\end{array}$ & $\begin{array}{l}183 \text { electrical } \\
\text { workers; } \\
3861 \text { non-electrical } \\
\text { workers }\end{array}$ & $\begin{array}{ll}0.9 & (0.5-1.7) \text { for lifetime } \\
& \text { depression }\end{array}$ & $\begin{array}{l}\text { Race, marital status, } \\
\text { education, alcohol use } \\
\& \text { duration of } \\
\text { employment }\end{array}$ \\
\hline $\begin{array}{l}\text { McMahan et al., } 1994 \\
\text { USA } \\
\text { Cross-sectional }\end{array}$ & $\begin{array}{l}\text { A sample of women living near a power line and one } \\
\text { block away from the power line in Orange County, } \\
\text { CA, USA } \\
\text { Depressive symptoms identified through } \\
\text { questionnaire and CES-D* scale. }\end{array}$ & $\begin{array}{l}\text { EMDEX** measurements at the } \\
\text { front door. Average for homes on } \\
\text { easement: } 4.86 \mathrm{mG} \text { and, one block } \\
\text { away: } 0.68 \mathrm{mG}\end{array}$ & $\begin{array}{l}76 \text { near the line; } \\
76 \text { away from the } \\
\text { line }\end{array}$ & $0.9(0.5-1.9)$ & Only women \\
\hline
\end{tabular}




\begin{tabular}{|c|c|c|c|c|c|}
\hline Reference & Study Base \& Subject Identification & Exposure & Numbers & RR (95\% C.L.) & Adjustments \\
\hline $\begin{array}{l}\text { Beale et al., } 1997 \\
\text { New Zealand } \\
\text { Cross-sectional }\end{array}$ & $\begin{array}{l}\text { Population living near transmission lines for at least } \\
6 \text { months, age between } 18 \text { and } 70 \\
\text { Houses with measurements of } 50 \mathrm{~Hz} \text { magnetic filed } \\
\text { flux densities at the gateway of over } 0.5 \mu \mathrm{T} \text { and } \\
\text { below } 0.3 \mu \mathrm{T} \text {. } \\
\text { Administered: GHQ }-28 \text { (including scores for major } \\
\text { depressions, anxiety, social dysfunction), 'Life } \\
\text { Changes' and 'Powerlines Project' questionnaires } \\
\text { together with attentional skills and memory tests. } \\
53 \% \text { of the invited households agreed to participate. }\end{array}$ & $\begin{array}{l}\text { Measurements at } 3 \text { places in rooms } \\
\text { where the subjects reported } \\
\text { spending on average } 1 \text { hour or more } \\
\text { daily. Average exposure and time } \\
\text { integrated (TI) exposure indices } \\
\text { were calculated for each subject. } \\
\text { For } 38 \text { subjects repeated } \\
\text { measurements were performed to } \\
\text { assure they were representative. } \\
\text { Local geomagnetic field was } \\
\text { measured at } 6 \text { places }(54.3-54.7 \mu \mathrm{T})\end{array}$ & 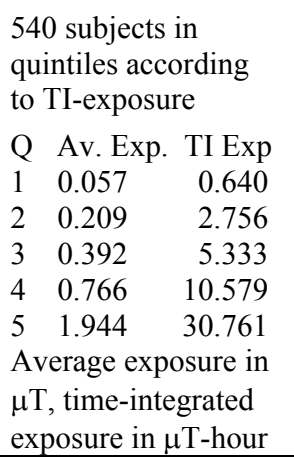 & \multicolumn{2}{|c|}{ 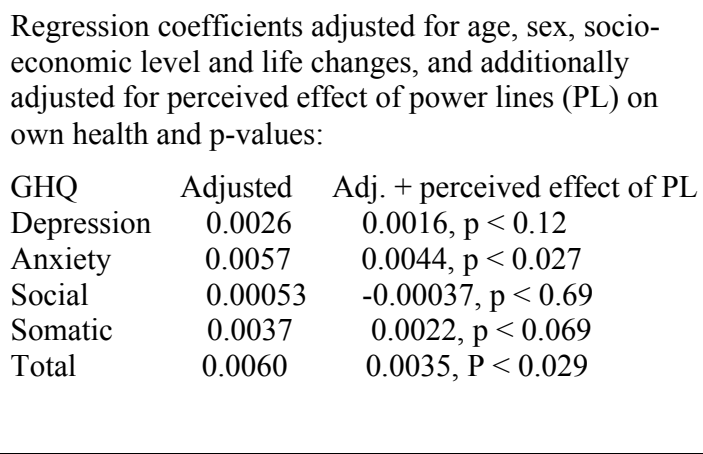 } \\
\hline $\begin{array}{l}\text { Verkasalo et al., } 1997 \\
\text { Finland } \\
\text { Cross-sectional }\end{array}$ & $\begin{array}{l}\text { Finnish twins who had answered the } \mathrm{BDI}^{\&} \text { in } 1990 \text {, } \\
\text { combined with the Finnish Transmission Line } \\
\text { Cohort study. } \\
77.5 \% \text { response rate }\end{array}$ & $\begin{array}{l}\text { Residential magnetic field estimated } \\
\text { from power lines near the homes. } \\
\text { Distance from line in } 1989 . \\
\text { Magnetic field in } 1989 \\
\text { Mean distance in } 1970-1989 \\
\text { Magnetic field-years } 1970-1989\end{array}$ & $\begin{array}{r}\text { Distance } \\
\text { from line } \\
>500 \mathrm{~m} \\
200-500 \mathrm{~m} \\
100-199 \mathrm{~m} \\
50-99 \mathrm{~m} \\
\quad<50 \mathrm{~m}\end{array}$ & \multicolumn{2}{|c|}{$\begin{array}{l}\text { BDI score not related to exposure. Adjustments of } \\
\text { mean BDI scores for sex, social class, education, } \\
\text { marital status, working outside the home, regular day } \\
\text { work, engagement in salary work, current smoking, } \\
\text { presence of heavy drinking, number of alcohol-related } \\
\text { pass-outs during the past year, life events scale and } \\
\text { social support scales }\end{array}$} \\
\hline $\begin{array}{l}\text { Bonhomme-Faivre et } \\
\text { al., } 1998 \\
\text { France } \\
\text { Cross-sectional }\end{array}$ & $\begin{array}{l}\text { Workers in a laboratory and adjacent offices situated } \\
\text { above electrical transformers and high tension } \\
(13 \mathrm{kV}) \text { cabling and above a power generator for at } \\
\text { least } 8 \mathrm{~h} / \mathrm{d} \text { for } 1-5 \text { years and controls from the same } \\
\text { enterprise and working on the same site as the } \\
\text { exposed } \\
\text { Self-rating questionnaire of potential neurovegetative } \\
\text { disorders }\end{array}$ & $\begin{array}{l}\text { EMF at } 50 \mathrm{~Hz} \text { measured every } 3 \mathrm{~h} \\
\text { when transformers were } \\
\text { functioning; } 3 \text { orthogonal measures; } \\
\text { Mean daily exposure over } 1 \text {-week } \\
\text { was calculated. } \\
50 \mathrm{~Hz} \text { field measured in } \mu \mathrm{T} \text { at the } \\
\text { floor level (FL) and } 1.5 \mathrm{~m} \text { above FL } \\
\text { in: } \quad \text { Lab } \quad \text { Adjacent offices } \\
\text { FL } \quad 1.2-6.6 \quad 0.2-0.3 \\
1.5 \mathrm{~m} \quad 0.3-1.5 \quad 0.09-0.12\end{array}$ & $\begin{array}{l}13 \text { exposed } \\
2 \text { subjects } 8 \mathrm{~h} / \mathrm{d} \text { in the } \\
\text { lab, } 11 \text { worked in } \\
\text { both the lab and the } \\
\text { adjacent offices } \\
13 \text { controls from the } \\
\text { same site, but } \\
\text { working only in } \\
\text { offices. }\end{array}$ & $\begin{array}{l}\text { Significant increase after } \\
1 \text { year of exposure in: } \\
\text { Depressive tendency } \\
\text { Melancholy } \\
\text { Irritability } \\
\text { Physical fatigue } \\
\text { Physical asthenia } \\
\text { Lipothymia } \\
\text { Decreased libido }\end{array}$ & $\begin{array}{l}\text { Controls matched on } \\
\text { socio-economic } \\
\text { category, sex and age }\end{array}$ \\
\hline
\end{tabular}

